\title{
Feeding practices in Australian early childhood education and care settings
}

\author{
Rebecca A Byrne ${ }^{1, *}$, Kimberley Baxter ${ }^{1}$, Sue Irvine ${ }^{2}$, Helen Vidgen ${ }^{1}$, \\ Danielle Gallegos ${ }^{1}$ (1), Elizabeth Martin ${ }^{3}$ and Stewart G Trost ${ }^{1}$ \\ 'Queensland University of Technology (QUT), School of Exercise and Nutrition Sciences, Faculty of Health, Centre for \\ Children's Health Research (CCHR), Kelvin Grove, QLD 4101, Australia: ${ }^{2}$ Queensland University of Technology \\ (QUT), School of Early Childhood and Inclusive Education, Faculty of Creative Industries, Education and Social Justice, \\ Kelvin Grove, QLD, Australia: ${ }^{3}$ Queensland University of Technology (QUT), School of Public Health and Social Work, \\ Faculty of Health, Kelvin Grove, QLD, Australia
}

Submitted 31 March 2021: Final revision received 8 September 2021: Accepted 21 September 2021: First published online 24 September 2021

\begin{abstract}
Objective: Feeding practices used by educators in Early Childhood Education and Care (ECEC) settings can influence the diet quality of young children. However, Australian data is scarce and limited to describing barriers to responsive feeding. This study describes the use of feeding practices amongst a group of Australian educators.

Design: Direct observation of feeding practices and assessment of centre policy were conducted using the 'Environment and Policy Assessment and Observation' tool. Self-reported feeding practices and demographic data were collected via online survey using the Childcare Food and Activity Practices Questionnaire.

Setting: Ten centre-based ECEC services in South East Queensland, Australia.

Participants: Educators working in ECEC.

Results: A total of 120 meals were observed and 88 educators provided self-report data ( $n 84$ female). Centre policy supported the use of responsive feeding practices, and this was reflected in the high frequency with which children could decide what and how much to eat, across both observed and self-report data as well as low levels of pressure to eat and use of food as a reward (observed at 19.9\% and $0 \%$ of meals). The only apparent discrepancy was regarding modelling. Median score for selfreported role-modelling was $5 \cdot 0(4 \cdot 3-5 \cdot 0)$ and educators were observed to sit with children at $75 \%$ of meals, however observed occasions of enthusiastic role modelling was only $22 \%(0-33 \cdot 3)$ of meals.

Conclusions: Research addressing how educators conceptualise feeding practices, as well under what circumstances they are used, particularly in centres with different models of food provision, may shed light on why modelling is rarely implemented in practice.
\end{abstract}

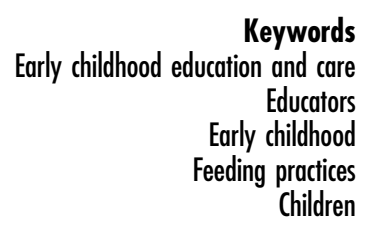

Birth to 5 years of age is a key window for children to learn about food and eating and the importance of optimal diet quality and mealtime environments in early childhood cannot be underestimated. The variety and type of food young children are exposed to, and opportunities to observe and imitate others' eating behavior can influence life-long food preferences and growth trajectory ${ }^{(1)}$. Children are born with the ability to self-regulate their energy intake ${ }^{(2)}$, highlighting the importance of providing children with nutritious food and allowing them to follow internal cues of hunger and satiety.
How young children are fed by adults can support or undermine self-regulation and research into the impact of parental feeding practices on child outcomes is wellestablished $^{(3,4)}$. 'Feeding practices' are the methods parents (and other carers) use at mealtimes to ensure children eat the amount and type of food that the caregiver deems is appropriate; and are broadly classified into three domains autonomy support, structure and coercive control ${ }^{(5)}$. Within the domains of autonomy support and structure, 'prompt, contingent and developmentally appropriate responses' to a child's hunger and satiety cues is identified 
as 'responsive feeding'(6). Adults, however, may ignore or misinterpret child cues and these practices fall within the domain of coercive control, for example pressuring the child to eat all the food on their plate, offering food in response to a child's distress or using food 'treats' as reward for appropriate behavior. When parents use feeding practices that are not responsive to a child's internal cues, it may teach children to eat for reasons other than hunger, disrupting self-regulation of energy intake with subsequent negative impacts on food preferences, dietary quality and long-term health consequences ${ }^{(7)}$.

The importance of the feeding practices used by educators in the Early Childhood Education and Care (ECEC) setting is increasingly being recognised. Use of practices by educators, that are consistent with autonomy support and structure, have been associated with higher intake of fruit and vegetables amongst children ${ }^{(8,9)}$. However, most of the literature describing the use of feeding practices by educators originates in the USA and Europe ${ }^{(10)}$ with very little known about the practices used by educators in Australian ECEC settings. This is despite almost one million Australian children under 5 years of age attending centrebased ECEC services, with $48 \%$ of children attending by age 2 years $^{(11)}$.

ECEC is a highly regulated sector in Australia. The workforce includes educators with a mix of qualifications, spanning from a 1-year Certificate III entry qualification to a 4-year teaching degree, with most educators holding a 2-year vocational Diploma of ECEC ${ }^{(12)}$. All ECEC services need to work within the National Quality Framework (NQF), which encompasses National Laws and Regulations and a quality rating system that drives continuous quality improvement ${ }^{(13)}$. Drawing on contemporary research, the NQF promotes child agency and autonomy supported by adult practices that are respectful of and responsive to individual child needs. This extends to pedagogical practices to support children's healthy development and lifestyle. A companion document to the NQF is the 'National Healthy Eating Guidelines and Physical Activity Recommendations for Early Childhood', commonly referred to as the 'Get Up \& Grow' guidelines ${ }^{(14)}$. These guidelines contain three recommendations related to feeding practices, which could all be considered to fall within the structure domain ${ }^{(5)}$ - that educators 'sit with children while they eat', 'eat and drink the same things as the children' and 'ensure that you are modelling bealthy eating behaviours'.

Two qualitative studies document barriers to the use of responsive feeding practices in the Australian ECEC setting ${ }^{(15,16)}$. In one study, educators reported being constrained by time and staffing, thereby having to establish a meal-time routine that met the ECEC centre's needs, rather than being responsive to an individual child's needs ${ }^{(16)}$. The second study was with pre-service educators ( $n$ 19) who reported a gap between knowledge about optimal feeding practices learned during training and what was observed when on practical placements ${ }^{(15)}$. Pre-service educators also noted that policies and procedures regarding mealtimes were not easily accessible to educators or parents. With many of a child's meals consumed in ECEC during their parent's working week, how children are fed by educators may have considerable influence on children's developmental trajectory. Therefore, the aim of this study is to describe the use of feeding practices amongst a group of Australian educators, using both direct observation of practices and policy and selfreport.

\section{Methods}

A convenience sample of thirteen ECEC centres across Brisbane and the Sunshine Coast in Queensland, Australia were invited to participate in a study which aimed to develop and evaluate a professional development program to promote responsive feeding practices known as NOURISH: Early Childhood Education (NOURISH:ECE). All were centre-based ECEC services, providing care for children aged 6 weeks to 5 years of age from approximately 7 am to 6 pm Monday to Friday. All centres were operated by one large organisation which manages over 300 centre-based ECEC services across the state of Queensland, therefore access to the centres was first negotiated with this organisation. Centre Directors were then approached by research staff who explained the study procedures. Directors decided whether to participate in consultation with their staff. The findings presented here are the baseline self-report and direct-observation data collected as part of the NOURISH:ECE project between December 2018 and June 2019.

Ten ECEC centres agreed to take part in the study. Centres varied in size, catering for between 46 and 125 children/d. According to publicly available data from the Australian Early Development Census ${ }^{(17)}$ all centres were in areas with a higher proportion of children who are considered developmentally vulnerable in two of the five domains of the Australian Early Development Census compared with the National average of $11 \%$. The Australian Early Development Census is a national indicator of early childhood development collected every 3 years. Children commencing their first year of compulsory education are scored on five domains, physical health and well-being; social competence; emotional maturity; language and cognitive skills and communication skills and general knowledge. The proportion of children who are developmentally vulnerable on two or more of the five domains can indicate how well early childhood health and development is supported within a region ${ }^{(18)}$. Four centres were in areas with a higher proportion of children who were developmentally vulnerable on two domains (16.4\%, 17.8\%, 18.8\% and $21.4 \%$ ) compared with the Queensland state average of $13.9 \%$. Two of the three centres that declined participation 
Table 1 Characteristics of educators providing self-reported data on feeding practices $(n 88)$

\begin{tabular}{lrr}
\hline Variable & $\%$ & $n$ \\
\hline Age & & \\
18-25 years & 15 & 13 \\
$26-35$ years & 16 & 14 \\
$36-45$ years & 34 & 30 \\
$46-55$ years & 17 & 15 \\
$56-65$ years & 16 & 14 \\
$<65$ years & 2 & 2 \\
Gender & 95 & 84 \\
Female & & \\
Education & 1 & 1 \\
Any level of high school & 25 & 22 \\
Certificate III & 50 & 44 \\
Diploma & 24 & 21 \\
Bachelor's degree & & 62 \\
Own children & 71 & 14 \\
Yes & & 13 \\
Room at centre & 16 & 19 \\
Babies & 15 & 25 \\
Toddlers & 22 & 17 \\
Pre-kindy & 28 & \\
Kindergarten & 19 & 59 \\
Casual or floating staff & & 22 \\
Employment status & 67 & 7 \\
Full time & 25 & \\
Part time & 8 & \\
Casual & & \\
\hline
\end{tabular}

were located in areas with fewer vulnerable children than the state or national averages.

After Centre Directors had agreed to take part, all individual educators (approximately 140 permanent or casual staff, working full-time or part-time) were invited to participate through the distribution of paper-based participant information sheets. Written informed consent was obtained to participate in the direct observation of mealtimes and/or an online survey. Of the 140 educators invited, $88 \mathrm{com}-$ pleted the online survey regarding feeding practices (response rate $63 \%$ ) with demographic data presented in Table 1 . Ninety-five percent were female ( $n 84)$, and median duration working in ECEC was 12 years (interquartile range $(\mathrm{IQR})=5-20)$.

\section{Direct observation of feeding practices}

Data were collected on provider practices and program policies using components of the 'Environment and Policy Assessment and Observation' tool (EPAO-2017) ${ }^{(19)}$. Slight modifications were made to the wording to suit the Australian ECEC context. The term educator was used instead of 'provider', and some food descriptions were altered e.g. crumbed instead of 'breaded', porridge instead of 'grits'. One additional question was 'Describe this meal? with the response options: progressive, standard or flexible. A progressive mealtime refers to an extended period in which the food is accessible to children and the decision about when and how long to engage in the mealtime is child-led. A standard mealtime refers to a set time frame where children are asked to finish playing/activities and come together for the meal or snack to be served. A flexible mealtime is one in which meal and snack times are approximate. Food can be provided earlier if children indicate that they are hungry or serving of food can be delayed if children are engaged in another activity.

Three research staff completed online training in the use of the EPAO- $2017^{(19)}$ via the website of the University of North Carolina in the USA ${ }^{(20)}$. Resources include a user manual and certification videos, with staff completing their certification against the gold standard videos on the site.

Trained staff then visited each ECEC centre alone or in pairs, over 1 to $2 \mathrm{~d}$ (depending on the size of the centre) and completed the modified nutrition components of the EPAO-2017 at morning tea, lunch and afternoon tea in each room. In Australian ECEC centres this typically consists of a 'Infant' room catering for children aged 6 weeks to 15 months, 'Toddlers' from 15 months to 3 years, 'Pre-kindergarten for children aged 3 to 4 years, and 'Kindergarten' which is for children in the year prior to starting formal schooling. Educators understood the purpose of the study to be that research staff wanted to describe what normally happens at mealtimes in ECEC. Direct observation occurred before the online survey, to avoid highlighting the specific focus on feeding practices. The date of each visit was pre-arranged with Centre Directors and research staff spent approximately $8 \mathrm{~h} / \mathrm{d}$ at each centre, arriving about $1 \mathrm{~h}$ before the first meal of the day was served, which was always morning tea in the 'Infant' room. In the 'Infant' room, the observed mealtimes were those in which solid foods were served to groups of infants and young children. Instances in which educators bottle-fed individual children were not included in the observation.

Centre nutrition policies were examined using the checklist in the 'Program policies' section of the EPAO2017. Any relevant sections of policy that described the use of feeding practices were extracted and are reported verbatim in the results.

\section{Self-report feeding practices}

Self-reported feeding practices were collected via an online survey using the feeding-related items from the Childcare Food and Activity Practices Questionnaire (CFAPQ) $)^{(21)}$. The CFAPQ consists of 41 food-related items which form eight scales - Restriction (six items); Monitoring (four items); Modelling/Encourage balance and variety (seven items); Involvement/Environment (five items); Teaching about nutrition (three items); Pressure to eat (four items); Child control (five items); Emotion regulation/Food as reward (five items) and a single item 'do you encourage the children to eat healthy foods before unhealthy ones?'. Items are measured on a five-point Likert scale ranging from disagree to agree, or never to always. Scale scores can range from one to five with a higher score representing greater use of that practice. 
Three changes to wording were made to suit the Australian setting with 'sweets' changed to desserts, 'cookies' to biscuits, and 'candy' to lollies. The survey was managed using REDCap (Research Electronic Data Capture $)^{(22,23)}$ hosted at the Queensland University of Technology and distributed to participants using their nominated email address.

\section{Data analysis}

Data from paper copies of the EPAO-2017 were entered into an excel spreadsheet by a research assistant, checked by RB for accuracy then exported to IBM SPSS v25. The proportion of mealtimes per ECEC centre at which an educator was observed using each feeding practice at least once during the meal was calculated. This approach has been used in other studies ${ }^{(24)}$.

Online survey data were exported from REDCap to IBM SPSS v25 for analysis. Scores were calculated for the seven scales of the CFAPQ by averaging items within each scale. Internal consistency was acceptable for restriction, $\alpha=0.72$; monitoring, $\alpha=0.91$; modelling/encourage balance and variety, $\alpha=0.77$; involvement/environment $\alpha=0.74$ and teaching about nutrition, $\alpha=0.70$. To improve consistency, the item 'I allow the children to help prepare meals' was removed from the Involvement/Environment scale. As the remaining four items relate to the type of food provided, this scale was referred to as 'Environment'. Similarly, the item 'I tell the children what to eat and what not to eat without explanation' was removed from the teaching scale. Internal consistency was fair for Pressure to eat, $\alpha=0.61$ and Child control, $\alpha=0.61$ (even with item 'If the children don't like the food that is being served, do you make something else? deleted to improve consistency) but was poor for Emotion regulation/Food as reward $(\alpha=0.57)$. These three scales also showed low internal consistency in the original validation study, with $\alpha=0.64$, 0.54 and 0.56 , respectively ${ }^{(21)}$.

\section{Results}

\section{Direct observation of feeding practices and policy}

A total of 120 meals were observed across the ten centres (morning tea, $n 42$; lunch $n 41$; afternoon tea, $n$ 37). Nine centres provided food for the children. Of these, one had a kitchen onsite, while the remainder used a catering company. Meals were not provided for educators. As centres were all administered by the same ECEC organisation, all shared the same nutrition policy. This policy covered the topics of nutrition, mealtimes, preparing meals, food storage and safety and bottle feeding, and applied to centres that provide food and those where children bring food from home. There was no information regarding the type, quality or amount of food that should be provided to children, with readers referred to the Australian Dietary Guidelines ${ }^{(25)}$ and
Table 2 Feeding practices addressed in the childcare provider's nutrition policy, and equivalent construct

\begin{tabular}{ll}
\hline $\begin{array}{l}\text { Extracts from the childcare provider's } \\
\text { nutrition policy }\end{array}$ & Feeding construct \\
\hline - Incorporate concepts regarding healthy & $\begin{array}{c}\text { Autonomy support or } \\
\text { promotion }\end{array}$ \\
- Build chices into the program. & \\
supporting them to choose what, when & \\
and how much they eat. & \\
- Encouraging children to eat healthy food \\
without instructing them to eat food they \\
do not like or to eat more than they want. \\
- Engaging children in conversation about \\
- Mealthy food choices. \\
- Model healthy eating habits when sharing Structure \\
mealtimes with children. \\
- Sitting with and engaging children in \\
conversations to create a relaxed and \\
enjoyable mealtime atmosphere. \\
- Being responsive to individual hunger \\
needs by allowing children to eat outside \\
routine mealtimes and feeding infants \\
individually at different times. \\
- Being patient with slow or "fussy" eaters. \\
- Never use food or drink to reward or \\
punish children. \\
- Do not withdraw food from children or \\
make judgments about food provided by \\
parents/guardians. \\
\hline
\end{tabular}

'Get Up and Grow' guidelines ${ }^{(14)}$. Excerpts from the nutrition policy relating to feeding practices are noted in Table 2 and broadly describe how to enact responsive feeding practices across the three domains of autonomy support, structure and coercive control ${ }^{(5)}$.

Of the 120 mealtimes observed, 39 (33\%) were standard, 59 (49\%) flexible and 22 (18\%) progressive. The progressive style of mealtime was most often implemented at morning and afternoon tea. Only three lunch mealtimes were classified as progressive and these were in rooms with older children ( $n 2$ kindergarten, $n 1$ pre-kindergarten). The most common way in which food was served to children across mealtimes was 'The educator served most foods and decided what size portions to give to the children', which was observed at 76 meals (63\%). The next two most frequently observed styles of food provision were used far less often - 'Children served themselves most/all foods and decided what size portions to take' at only 18 meals (15\%) and 'Children brought food from home' at 14 meals (12\%).

The median proportion of mealtimes per centre at which educators were observed to use an authoritative feeding style was high, at $78.9 \%(\mathrm{IQR}=66.7-91.7)$. An authoritative feeding style is defined in the EPAO-2017 as a balance between encouraging children to eat healthy foods and allowing children to make their own food choices, as well as using reason and education, rather than bribes or threats ${ }^{(19)}$. This is consistent with the low proportion of meals at which use of reward or pressure to eat were seen - the proportion of meals per centre at which 
Table 3 Proportion of mealtimes ( $n 120$ meals) per ECEC centre $(n 10)$ at which an educator was observed using each feeding practice at least once during the meal

\begin{tabular}{|c|c|c|c|}
\hline Practice & $\%$, Median & IQR & Feeding construct \\
\hline \multicolumn{4}{|l|}{ Did the educator eat any of the following foods in front of the children? } \\
\hline The educator ate the same foods as the children & $19 \cdot 6$ & $5 \cdot 8-33 \cdot 3$ & \multirow[t]{2}{*}{ Structure } \\
\hline The educator ate fruits or vegetables & 3.3 & $0-14.9$ & \\
\hline \multicolumn{4}{|l|}{ How often were the following interactions observed between the educator and the children? } \\
\hline The educator sat with the children & $75 \cdot 0$ & $70 \cdot 2-83 \cdot 7$ & \multirow[t]{2}{*}{ Structure } \\
\hline The educator enthusiastically role modelled eating healthy foods & $22 \cdot 2$ & $0-33 \cdot 3$ & \\
\hline \multicolumn{4}{|l|}{ The educator encouraged children to try the foods on their plates } \\
\hline Mean & $63 \cdot 6$ & & \multirow{3}{*}{$\begin{array}{l}\text { Autonomy support or } \\
\text { promotion }\end{array}$} \\
\hline $\mathrm{SD}$ & $18 \cdot 2$ & & \\
\hline The educator praised a child for eating healthy foods & $12 \cdot 7$ & $5 \cdot 8-19 \cdot 2$ & \\
\hline \multicolumn{4}{|l|}{ The educator talked with the children about the foods they were eating } \\
\hline Mean & 71.5 & & \\
\hline SD & 9.33 & & \\
\hline \multicolumn{4}{|l|}{ How often did the educator support or hinder children's self-regulation? } \\
\hline The educator pressured a child to eat & $19 \cdot 9$ & $12 \cdot 5-27 \cdot 1$ & \multirow[t]{2}{*}{ Coercive control } \\
\hline The educator required the child sit at the table until he/she cleaned their plate. & 0 & $0-0$ & \\
\hline \multicolumn{4}{|l|}{ How often did the educator use rewards or bribes? } \\
\hline The educator promised something other than food for eating & 0 & $0-6 \cdot 8$ & \multirow[t]{4}{*}{ Coercive control } \\
\hline The educator used food as a reward or bribe for eating a less preferred food & 0 & $0-11.8$ & \\
\hline The educator used food as a reward or withheld food as a punishment for behavior & 0 & $0-0$ & \\
\hline The educator used food to calm an upset child & 0 & $0-7 \cdot 1$ & \\
\hline
\end{tabular}

educators were observed to use 13 different feeding practices is shown in Table 3. While educators at each centre frequently sat with children and discussed the foods they were eating (median of $75 \%$ and $71.5 \%$ of meals respectively), occurrence of enthusiastic role modelling ( $22.2 \%)$, eating the same foods as children (19.6\%) or being seen to eat fruit or vegetables $(3.3 \%)$ was much less. Of note, in two centres, no educators were observed eating the same food as children at any meal. Across all ten centres, no educators were observed eating a 'complete' meal with children, i.e. modelling eating their own meal from hunger to satiety. The number of occasions on which educators were observed to eat unhealthy foods (classified in the EPAO-2017 as fast food, sweet snack, salty snack or sweetened beverage ${ }^{(19)}$ ) was so infrequent, that data are not presented in the table - sweet snack, $n 2$ mealtimes; sweetened beverage, $n 1$.

\section{Self-report feeding practices}

Scores for feeding practice scales (median and IQR) are reported in Table 4. Educators reported high levels of modelling of healthy eating (median score of 4.9 , out of a possible $5, \mathrm{IQR}=4 \cdot 4-5 \cdot 0)$ and low levels of pressure to eat ( median $=2 \cdot 0, \mathrm{IQR}=1 \cdot 3-2 \cdot 5$ ). Scores on the 'environment' and 'teaching' scales were also high, both with a median score of $4 \cdot 5$ (IQR $=3 \cdot 5-5 \cdot 0$ and 4.0-5.0, respectively), indicating that educators felt most foods provided at their centre were healthy and they discussed healthy eating with the children.

\section{Discussion}

With almost one million Australian children attending centre based ECEC services each day ${ }^{(11)}$, educators have
Table 4 Self-reported feeding practices of educators ( $n$ 88) measured using the childcare food \& activity practices questionnaire (CFAPQ) ${ }^{(21)}$

\begin{tabular}{|c|c|c|c|}
\hline Scale & $\begin{array}{l}\text { Score* }^{*} \\
\text { median }\end{array}$ & IQR & Feeding construct \\
\hline Teaching & 4.5 & $4 \cdot 0-5 \cdot 0$ & \\
\hline $\begin{array}{l}\text { Encourage healthy } \\
\text { foods } \S, \|\end{array}$ & $4 \cdot 0$ & $4.0-5 \cdot 0$ & $\begin{array}{l}\text { Autonomy support or } \\
\text { promotion }\end{array}$ \\
\hline Monitoring§ & 3.8 & $2 \cdot 6-4.5$ & Structure \\
\hline Modellingt & 4.9 & $4.4-5.0$ & \\
\hline Environment† & 4.5 & $3.5-5.0$ & \\
\hline Child control§ & 3.5 & $3 \cdot 0-3 \cdot 8$ & \\
\hline Restriction† & 3.0 & $2.5-3.5$ & Coercive control \\
\hline Pressure to eat $†$ & $2 \cdot 0$ & $1 \cdot 3-2 \cdot 5$ & \\
\hline
\end{tabular}

*Possible score of $1-5$.

†ltems measured on five-point Likert scale: disagree, slightly disagree, neutral, slightly agree, agree.

$\ddagger n 87$.

§ltems measured on five-point Likert scale: never, rarely, sometimes, mostly, always.

\|Single item 'do you encourage the children to eat healthy foods before unhealthy ones?'.

an important role in supporting children's health and well-being through the creation of optimal mealtime environments. This study is one of the first to describe the feeding practices used by educators in Australian ECEC settings, using both direct observation and self-report. The core practice of responsiveness was embedded within the ECEC organisation's nutrition policy, and overall, educators reported, and were observed to use, practices that are consistent with 'responsive feeding'(6). The mealtime environment within these centres reflects the intent of Australia's $\mathrm{NQF}^{(13)}$, which promotes child agency and autonomy and the need for pedagogical practices that are responsive to individual children.

While most mealtimes were adult-led, and the "educator served most foods and decided what size portions to give to 
the children', children were largely able to decide which of these foods to eat and how much to consume. Practices that fit within the domain of coercive control ${ }^{(5)}$ were rarely observed, such as pressuring a child to eat more, or using food as a reward or bribe. This was consistent with the low levels of pressure on children to eat reported by educators. However, educators also reported often encouraging the children to eat healthy foods before unhealthy ones, with the item having a median score of $4.0 \quad(\mathrm{IQR}=4 \cdot 0-5 \cdot 0)$. Some health practitioners have expressed concern about whether this type encouragement could be more consistent with pressure to eat or reward for eating, depending on the intent of the adult using the practice ${ }^{(26)}$.

Consistent with the $\mathrm{NQF}^{(13)}$, centre policy supported the use of practices which were aligned with autonomy support and appropriate levels of structure ${ }^{(5)}$. The organisational policy included statements such as ‘build children's agency and autonomy by supporting them to choose what, when and how much they eat' and encouraging educators to sit with and engage children in conversations, particularly around healthy food choices. These practices were frequently observed by the research team - educators at each centre frequently sat with children and discussed the foods they were eating (median of $75 \%$ and $71.5 \%$ of meals respectively), and educators self-reported high levels of agreement with the 'teaching' scale of the $\mathrm{CFAPQ}^{(21)}$, in which items relate to discussing the health and nutritional value of foods with children. Scores on the CFAPQ 'environment' scale were also high, indicating that educators felt the majority of foods provided at their centre were healthy. This may explain why scores for 'restriction' and 'monitoring' were 3.0 and 3.5 respectively on the $1-5$ scale. Due to the presence of an overall healthy food environment, educators were generally neutral about the need to guide or regulate children's intake of desserts or biscuits, and only sometimes needed to monitor the intake of high-fat foods or sugary drinks. However, there is a need for further research to examine the use of 'restriction' and 'monitoring' (and feeding practices more broadly) in centres where children bring meals from home in lunchboxes. There is no published data on the number of ECEC centres in Australia that provide food $v$. those in which children bring lunchboxes. In a study of 17 Australian ECEC services in which the contents of 355 children's lunchboxes were examined, less than $1 \%$ of lunchboxes met setting-specific nutrition guidelines and over half contained discretionary foods ${ }^{(27)}$. It is plausible that educators may use 'restriction', 'monitoring' and 'encouraging the children to eat healthy foods before unhealthy ones' if they perceive that lunchbox contents are not consistent with healthy eating. Another study by the same research group ${ }^{(28)}$, examined educator practices in twenty-two ECEC lunchbox centres ( $n 448$ children), by using twenty-one items from the EPAO-2017 to create a composite score representing 'use of feeding practices that support children's healthy eating'. The mean score was $1.86(\mathrm{SD}=0.22)$ on a scale of $1-3$, but the frequency of use of specific practices was not reported.

Imitation of other people's behavior by children is a powerful way to facilitate learning (i.e. observational learning $\left.^{(1)}\right)$, and it is thought this can be harnessed to promote food acceptance, particularly in relation to vegetables ${ }^{(29)}$. Role modelling by educators is acknowledged as an essential component of multi-level interventions to promote healthy eating amongst young children in $\operatorname{ECEC}^{(10,30)}$ and specific guidance regarding modelling is incorporated into the 'Get Up and Grow' practice guidelines for educators ${ }^{(14)}$. One area in the NOURISH:ECE study in which there appeared to be a discrepancy between centre policy, self-reported and observed feeding practices, was role modelling. Centre policy stated, 'model healthy eating habits when sharing mealtimes with children' and levels of selfreported modelling were very high, with a median score of 4.9 (IQR 4.4-5.0). However, the direct observation of practices indicated that enthusiastic role modelling occurred at only approximately one in every five meals observed at each ECEC centre (22.2\%). Similarly, as these centres did not make provision for educator meals, educators were not often observed eating the same foods as children (median of $19.6 \%$ meals per centre) and rarely seen eating fruits or vegetables ( $3.3 \%$ of meals per centre). These findings contrast with those in other countries. Direct observation of practices in nine ECEC centres in the Netherlands using the EPAO-2017 revealed high levels of role modelling ${ }^{(24)}$. Of 135 eating occasions observed (which included morning tea, lunch and afternoon tea), educators ate with children at $76.9 \%$ meals and ate the same food at $50 \%$. In the USA, researchers using the Meal-time Observation in Childcare tool ( $n 10$ centres) $)^{(31)}$ observed educators enthusiastically role model healthy eating at $58 \%$ of meals and consuming fruit or vegetables at $24 \%$ and $39 \%$ of eating occasions. However, both studies found more frequent use of pressure to eat by educators, namely 'times the child was pressured or encouraged to eat more' at $52.3 \%$ of meals ${ }^{(24)}$ and 'pressured child to eat when they refused' at $88 \%{ }^{(31)}$ compared with $19.9 \%$ of eating occasions in the current sample.

International discrepancies could be due to many reasons - differences in measurement, cultural differences in the application of feeding practices, or differences in training and policy governing educators in different jurisdictions. Two qualitative studies of feeding practices in Australian ECEC settings, educators and trainees report that rigid centre policies prevent the use of responsive feeding in practice ${ }^{(15,16)}$. This is unlikely to be the case in the current study given that the ECEC operator's policy explicitly supports modelling, but there may be other workplace, professional and personal barriers that prevent educators from modelling, regardless of how much they value this practice. For example, key educators need to take breaks at scheduled times, often leaving casual staff to cover meals. The opportunity for role modelling by familiar and trusted 
adults is potentially lost. Malek-Lasater et al. also note the discrepancy in the promotion of optimal mealtime practices between health and education disciplines ${ }^{(31)}$ arguing that 'the use of responsive feeding practices needs to be incorporated into quality measurements and teaching practices endorsed by education-related entities in order to ensure they are understood and implemented in the class-room'.

Food service also plays an important role. Meals were not provided to educators at the centres participating in this study and educators may be reluctant to consume any of the food that is provided for children. The style of food service has implication for how meals are served to children. A centre that prepares food in bulk to provide meals to a large number of children, may be less able to implement a progressive style of meal, compared with a centre in which children bring lunch boxes from home. Anecdotally, the use of progressive meals is increasing. The idea that children are solely responsible for deciding when and how long to engage in mealtimes according to their internal cues of hunger and satiety, is consistent with supporting a child's self-regulation of energy intake. However, the burden on educators to safely implement this in rooms with infants and toddlers is likely to be significant, and perhaps why progressive meals were rarely used at lunchtime in the current study, and only with older children who are largely independent with self-feeding. The use of progressive meals represents less 'structure'(5) which may also impact the atmosphere of meals, with fewer opportunities for discussion amongst groups of children, and role modelling by educators and peers. Trade-offs might be required to balance the use of progressive meals with the social goal of eating together as an ECEC community ${ }^{(32)}$. Exploring the differential use of structure, autonomy supportive and controlling practices across the age and developmental groupings are typically seen in ECEC - infants, toddlers, pre-kindergarten and kindergarten - is an important premise for future research which can inform training and education programs for educators.

Other opportunity costs such as providing meals to staff to facilitate role modelling of healthy food intake could also be considered. Economic evaluation methods such as costeffectiveness modelling can inform decisions about implementation of responsive feeding policies and quantify the trade-offs associated with different approaches. The characteristics of centres where responsive feeding practices are successfully implemented could be compared with centres where responsive practices less frequently, thereby identifying potential avenues for interventions to promote and support optimal feeding environments.

\section{Strengths and limitations}

The direct observation of feeding practices is a strength of this study, as it overcomes the reporting bias associated with self-report practices. Social desirability bias may explain the high level of role modelling reported in this sample, and the discrepancy between observed and selfreported practices. However, the limitations of this study mean that this apparent discrepancy must be interpreted with caution. Practices were observed with the 'meal' as the unit of interest and reported by centre. There was no direct comparison of an individual's self-reported level of a given feeding practice with the observation of that educator's behaviour. As educators could choose to participate in one or both activities, the sample for self-report $v$. observed data would be slightly different.

There are also limitations regarding the measurement tools used. It is not known whether educators are conceptualising practices in the same way as intended in the questionnaire items. There is also an absence of tools to assess feeding practices in the Australian ECEC setting with adequate evidence of validity and reliability. In the interim, this study provides insight into the applicability of existing validated tools that may be used to assess educator practices in Australia.

There are also limitations regarding the use of EPAO$2017^{(19)}$. New items were recently developed and tested in family day-care homes, to capture educator feeding practices more comprehensively across the domains of autonomy support, structure and coercive control ${ }^{(33)}$. The EPAO-2017 also does not consider the frequency with which a practice occurs during an eating occasion. A practice need only occur once at a meal time to score 'yes' on an individual item. Future studies which examine the impact of educator practices on child outcomes in Australia could consider using tools that assess the intensity of a given feeding practice. One such example is 'Table Talk' which characterises verbal interactions at meal times ${ }^{(34)}$.

All centres were operated by one large organisation, and all but one provided food, which may limit variability in the types of practices seen. Investigation of feeding practices used in diverse types of centres across all Australian states and territories, is an area for future research e.g. private forprofit centres $v$. private not for profit, large providers $v$. small single service operators; as well as exploring educator practices in services in which children bring food to the centre in lunchboxes.

\section{Conclusions}

This is the first study to quantitatively assess the feeding practices used by educators in Australian ECEC centres using both direct observation and self-report. Centre polices supported the use of responsive feeding practices, and this was reflected in the high frequency with which children could decide what and how much to eat, across both observed and self-report data as well as low levels of pressure to eat and use of food as a reward. The only apparent discrepancy was in regard to role modelling. Despite policy support, and high levels of educator 
self-report, frequency of observed role modelling was low. Further research addressing how educators conceptualise feeding practices, as well as how and under what circumstances they are used, may shed light on why this important aspect of mealtimes is rarely implemented in practice.

\section{Acknowledgements}

Acknowledgements: The authors acknowledge the First Nations owners of the land on which this research was conducted, the Turrbal, Yugara and Gubbi Gubbi peoples. We acknowledge the support of Alison Evans and Dr Pam Spall, and Andrew Resetti from Children's Health Queensland. Thank you to research assistants Dr Kamila Davidson and Susannah Ayre. A sincere thank you to the Centre Directors and Educators who participated in this project for giving so generously of your time. Financial support: This research was funded by the Children's Hospital Foundation (WWHSR0052018) in the 2018 Woolworths Nutrition-Related Health Services Research Grant Round. The Children's Hospital Foundation had no role in the design, analysis or writing of this article. Conflict of interest: Funding for this grant round was provided to the Children's Hospital Foundation via a philanthropic donation from Woolworths. Applications for funding were evaluated independently by the Research Grants Committee of the Children's Hospital Foundation. Woolworths had no input into the awarding of funds or the design and conduct of this research. Authorship: All authors had input into the design and conduct of this study. R.B. and K.B. collected the data. R.B. completed data analysis and drafted the manuscript. All authors contributed to the writing of the manuscript and approved the final version. Ethics of human subject participation: This study was conducted according to the guidelines laid down in the Declaration of Helsinki and all procedures involving research study participants were approved by the Children's Health Queensland Human Research Ethics Committee [LNR/2018/QCHQ/45429]. Written informed consent was obtained from all participants.

\section{References}

1. Mura Paroche M, Caton SJ, Vereijken CMJL et al. (2017) How infants and young children learn about food: a systematic review. Front Psychol. Published online: 25 July 2017. doi: 10.3389/fpsyg.2017.01046.

2. Frankel LA, Hughes SO, O'Connor TM et al. (2012) Parental influences on children's self-regulation of energy intake: insights from developmental literature on emotion regulation. J Obes. Published online: 28 March 2012. doi: 10. 1155/2012/327259.

3. Frankel LA, Powell E \& Jansen E (2018) The relationship between structure-related food parenting practices and children's heightened levels of self-regulation in eating. Child Obes 14, 81-88.

4. Rollins BY, Savage JS, Fisher JO et al. (2016) Alternatives to restrictive feeding practices to promote self-regulation in childhood: a developmental perspective. Pediatr Obes 11, 326-332.

5. Vaughn AE, Ward DS, Fisher JO et al. (2016) Fundamental constructs in food parenting practices: a content map to guide future research. Nutr Rev 74, 98-117.

6. DiSantis K, Hodges E, Johnson S et al. (2011) The role of responsive feeding in overweight during infancy and toddlerhood: a systematic review. Int J Obes 35, 480-492.

7. Wood AC, Blissett JM, Brunstrom JM et al. (2020) Caregiver influences on eating behaviors in young children: a scientific statement from the American Heart Association. J Am Heart Assoc. Published online: 11 May 2020. doi: 10.1161/JAHA. 119.014520 .

8. Anundson K, Sisson SB, Anderson M et al. (2018) Staff food-related behaviors and children's tastes of food groups during lunch at child care in Oklahoma. J Acad Nutr Diet 118, 1399-1407.

9. Gubbels J, Gerards S \& Kremers S (2015) Use of food practices by childcare staff and the association with dietary intake of children at childcare. Nutrients 7, 2161-2175.

10. Ward S, Bélanger M, Donovan D et al. (2015) Systematic review of the relationship between childcare educators' practices and preschoolers' physical activity and eating behaviours. Obes Rev 16, 1055-1070.

11. Australian Bureau of Statistics (2018) Childhood Education and Care, Australia, June 2017; available at https://www.abs. gov.au/statistics/people/education/childhood-educationand-care-australia/latest-release (accessed January 2021).

12. The Social Research Centre (2017) 2016 Early Childhood Education and Care National Workforce Census. VIC, Australia: Department of Education and Training.

13. Australian Children's Education and Care Quality Authority (2020) Guide to the National Quality Framework. Sydney, Australia: ACECQA.

14. Australian Government \& Department of Health and Ageing (2009) Get Up \& Grow: Healthy Eating and Physical Activity for Early Childhood. Director/Coordinator Handbook. Commonwealth of Australia: Australian Government, Department of Health and Ageing.

15. Love P, Walsh M \& Campbell KJ (2020) Knowledge, attitudes and practices of Australian trainee childcare educators regarding their role in the feeding behaviours of young children. Int J Environ Res Public Health. Published online: 25 May 2020. doi: 10.3390/ijerph17103712.

16. McGuire J, Irvine S, Smith J et al. (2021) Australian early childhood educators and infant feeding: a qualitative analysis using social cognitive theory. Early Child Dev Care 191, $773-788$.

17. Department of Education and Training (2019) Australian Early Development Census. Canberra, Australia: AEDC; available at https://www.aedc.gov.au/about-the-aedc (accessed February 2021).

18. Brinkman SA, Gregory TA, Goldfeld S et al. (2014) Data resource profile: the Australian early development index (AEDI). Int J Epidemiol 43, 1089-1096.

19. Ward D, Hales D, Haverly K et al. (2008) An instrument to assess the obesogenic environment of child care centers. Am J Health Behav 32, 380-386.

20. The Children's Healthy Weight Research Group (2018) Resources: UNC Center for Health Promotion and Disease Prevention. Chapel Hill: The University of North Carolina; available at https://chwr.web.unc.edu/resources/ (accessed November 2018).

21. Gubbels JS, Sleddens EFC, Raaijmakers LCH et al. (2015) The child-care food and activity practices questionnaire (CFAPQ): development and first validation steps. Public Health Nutr 19, 1964-1975.

22. Harris PA, Taylor R, Minor BL et al. (2019) The REDCap consortium: building an international community of software 
platform partners. J Biomed Inform. Published online: 9 May 2019. doi: 10.1016/j.jbi.2019.103208.

23. Harris PA, Taylor R, Thielke R et al. (2009) Research electronic data capture (REDCap) - a metadata-driven methodology and workflow process for providing translational research informatics support. J Biomed Inform 42, 377-381.

24. Gubbels JS, Kremers SPJ, Stafleu A et al. (2010) Child-care environment and dietary intake of 2- and 3-year-old children. J Hum Nutr Diet 23, 97-101.

25. Australian Government, National Health and Medical Research Council \& Department of Health and Ageing (2013) Australian Dietary Guidelines. Canberra, Australia: National Health and Medical Research Council.

26. Daniels LA (2019) Feeding practices and parenting: a pathway to child health and family happiness. Ann Nutr Metab 74, Suppl. 2, S29-S42.

27. Pearson N, Wolfenden L, Finch M et al. (2020) A crosssectional study of packed lunchbox foods and their consumption by children in early childhood education and care services. Nutr Diet. Published online: 24 August 2020. doi: 10. 1111/1747-0080.12632.

28. Barnes C, Yoong SL, Wolfenden L et al. (2021) The association between Australian childcare centre healthy eating practices and children's healthy eating behaviours: a cross-sectional study within lunchbox centres. Nutrients. Published online: 30 March 2021. doi: 10.3390/nu13041139.
29. Barends C, Weenen H, Warren J et al. (2019) A systematic review of practices to promote vegetable acceptance in the first 3 years of life. Appetite 137, 174-197.

30. Matwiejczyk L, Mehta K, Scott J et al. (2018) Characteristics of effective interventions promoting healthy eating for preschoolers in childcare settings: an umbrella review. Nutrients. Published online: 1 March 2018. doi: 10.3390/ nu10030293.

31. Malek-Lasater AD, Kwon K-A, Horm DM et al. (2021). Supporting children's healthy development during mealtime in early childhood settings. Early Childhood Educ J. Published online: 7 January 2021. doi: 10.1007/s10643-020-01137-2.

32. Harte S, Theobald M \& Trost SG (2019) Culture and community: observation of mealtime enactment in early childhood education and care settings. Int J Behav Nutr Phys Act. Published online: 22 August 2019. doi: 10.1186/s12966019-0838-x.

33. Tovar A, Vaughn AE, Fisher JO et al. (2019) Modifying the environment and policy assessment and observation (EPAO) to better capture feeding practices of family childcare home providers. Public Health Nutr 22, 223-234.

34. Swindle T, Phelps J, McBride NM et al. (2021) Table talk: revision of an observational tool to characterize the feeding environment in early care and education settings. BMC Public Health. Published online: 7 January 2021. doi: 10. 1186/s12889-020-10087-8. 